\title{
Aplicações de Jogos que Podem ser Usados como Recursos Educativos no Ensino da Química Orgânica
}

\begin{abstract}
Game apps that can be used as educational resources in teaching organic chemistry. Organic Chemistry is a topic where many students demonstrate learning difficulties, being also a discipline with a high failure in the case of higher education. The use of active learning methods can be a strategy to motivate students in its study. This includes the use of educational games, namely games apps that have organic chemistry as a theme. This article aims to make a non-exhaustive systematization of game apps that can be very useful in teaching organic chemistry in and outside the classroom, whether in secondary or higher education.
\end{abstract}

Os alunos em geral demonstram dificuldades na aprendizagem dos tópicos de química orgânica, sendo esta uma disciplina com elevado insucesso escolar no caso do ensino superior. O uso de métodos de aprendizagem ativa poderá ser uma estratégia para motivar os alunos para o seu estudo/aprendizagem. Inclui-se neste âmbito a utilização de jogos educativos, nomeadamente as aplicações de jogos que têm a química orgânica como temática. Este artigo tem como objetivo fazer uma sistematização, não exaustiva, de aplicações de jogos que podem ser muito úteis no ensino da química orgânica em sala de aula, ou fora dela, quer no ensino secundário quer no ensino superior.

\section{Introdução}

A aprendizagem ativa tem sido considerada como uma estratégia promissora para melhorar os resultados obtidos na sala de aula, em particular no contexto da química orgânica [1]. Por método de aprendizagem ativa entende-se qualquer método de instrução que ativamente envolve os alunos no seu processo de aprendizagem em oposição à passividade de apenas assistir a uma aula. Ou seja, os alunos são encorajados não apenas a ouvir e ver, mas também a falar, ler e como consequência a refletir nos conteúdos, questionando-se e clarificando, processo que intensifica a aquisição de conhecimentos.
}

Os jogos providenciam uma abordagem interessante à aprendizagem ativa dado que juntam a construção do conhecimento utilizando uma atividade lúdica a uma alegre competição. 0 sucesso desta estratégia pode ser confirmado pelo aumento do número de jogos que são utilizados para ensinar diferentes tópicos, como por exemplo, a tabela periódica [2], química geral [3], química orgânica [4-6], grupos funcionais [4], síntese química [7,8], entre outros.

Os jogos podem ser classificados de acordo com o tema da matéria que tratam (esta classificação foi feita no parágrafo anterior), ou pela forma como se 
apresentam (jogo de tabuleiro, jogo de cartas, jogo de dados, puzzles e jogos eletrónicos) [9].

Embora o uso de telemóveis na sala de aula seja ainda controverso, o seu potencial no ensino da química tem vindo a ser demonstrado nos últimos anos. 0 uso alargado de smartphones pelos alunos $[10,11]$, bem como de outros aparelhos eletrónicos portáteis, como computadores e tablets, constitui uma excelente oportunidade para utilizar aplicações de jogos com fins educativos promovendo deste modo a interatividade entre os alunos e entre os alunos e o professor.

O presente artigo tem como objetivo fazer uma revisão sistemática destas aplicações que têm como temática a química orgânica e que podem ser usados em sala de aula ou fora dela, quer no ensino secundário quer no ensino superior. Salienta-se que esta revisão não é exaustiva, mas apenas focada nas aplicações, que para as autoras, apresentam uma maior relevância/utilidade para o ensino da química orgânica.

\section{Aplicações de jogos para o ensino da Química Orgânica}

As aplicações de jogos desenvolvidas para o ensino da química orgânica abrangem vários tópicos, desde a nomenclatura até à síntese. Na Tabela 1 apresenta-se uma sistematização dessas aplicações, na qual, entre outras informações se indica o(s) ano(s) de escolaridade no qual cada aplicação pode ser utilizada, o idioma no qual se encontra, bem como a sua disponibilidade em termos do seu custo (valor monetário).

Tabela 1 - Sistematização de aplicações

desenvolvidas para o ensino da química orgânica.

\begin{tabular}{|c|c|c|c|c|}
\hline Aplicação & Temática abordada & Escolaridade & Idioma ${ }^{a}$ & Disponibilidade ${ }^{\mathrm{b}}$ \\
\hline Chirality-2 & $\begin{array}{c}\text { Grupos funcionais; } \\
\text { Classificação da estrutura; } \\
\text { Forças intermoleculares; } \\
\text { Isómeros; Centros quirais; } \\
\text { Nomenclatura }\end{array}$ & $10 .^{\circ}$ ano $/ \mathrm{U}$ & EN & $\mathrm{F}$ \\
\hline Mechanisms & $\begin{array}{l}\text { Mecanismos de substituição; } \\
\text { Mecanismos de eliminação }\end{array}$ & $12 .^{\circ}$ ano $/ \mathrm{U}$ & EN & GL \\
\hline Chairs & Conformações do ciclo-hexano & U & EN & $P$ \\
\hline $\begin{array}{l}\text { MILAGE } \\
\text { Aprender+ }\end{array}$ & Diversa & $7 .^{\circ} \mathrm{ano} / \mathrm{U}$ & PT/EN & GA \\
\hline $\begin{array}{l}\text { Nomenclature } \\
\text { Bets }^{c}\end{array}$ & Nomenclatura & $10 .^{\circ} \mathrm{ano} / \mathrm{U}$ & PT/EN & G \\
\hline Isomers & Isómeros & $10 .^{\circ}$ ano $/ U$ & PT/EN & $P$ \\
\hline
\end{tabular}

aPT - Português: EN - Inglês. bF - Grátis; GL - Grátis para funcionalidades limitadas; P - Pago; GA - Grátis com autorização do autor. 'Página na internet: Idse.ufc.br/nomenclaturebets.
O Chirality-2 é uma aplicação de um jogo que cobre múltiplos aspetos da química orgânica introdutória podendo ser utilizado no ensino secundário e superior. Os tópicos abordados são a identificação de um grupo funcional, a classificação da estrutura, as forças intermoleculares, os isómeros, os centros quirais e a nomenclatura. A aplicação usa interfaces touch-screen de arrastar e soltar para que os utilizadores resolvam quebra-cabeças e respondam a perguntas. No caso da identificação do grupo funcional e das forças intermoleculares, os jogadores recebem uma imagem de uma molécula e usam uma interface de arrastar e soltar para mover blocos com o nome de grupos funcionais ou da força intermolecular para o local correto. Já no caso da classificação da estrutura, é apresentada ao jogador uma tabela exibindo nomes e estruturas, e este deve fazer corresponder a estrutura ao respetivo nome. Os pares contêm imagens/nomes de aminas primárias, secundárias ou terciárias, álcoois, halogenetos de alquilo e carbocatiões. Os pares corretos são removidos quando selecionados. Pares incorretos não são removidos. No isomerismo, o jogador recebe cinco pares de isómeros (de um grupo de 18) e deve identificar o seu tipo. Após o envio da resposta, o jogador recebe um feedback instantâneo sobre se a escolha foi ou não correta. No tópico dos centros quirais, o jogador é apresentado a uma molécula, na qual tem de identificar os centros quirais existentes. O jogo mostra quais dos átomos selecionados foram identificados corretamente ou incorretamente, bem como aqueles que deveriam ter sido identificados, mas não o foram. Ainda pergunta adicionalmente quantos estereoisómeros a molécula possui. No caso da nomenclatura de moléculas, são mostradas ao jogador 10 imagens de moléculas orgânicas, para as quais deve selecionar o nome correto entre quatro opções [12].

o Chairs foi desenhado com o objetivo de ensinar as conformações do ciclo-hexano. Os estudantes aprendem os conceitos por tentativa e erro enquanto jogam. Ao jogador são apresentados dois isómeros conformacionais diferentes do ciclo-hexano. Uma ligação é mostrada numa das conformações e um círculo pulsante marca a posição correspondente na outra conformação. 0 jogador deve desenhar a ligação nesta última conformação com o ângulo correto, axial ou equatorial. Se a ligação desenhada não estiver dentro de um intervalo estreito próximo do ângulo correto, será mostrada a vermelho. Quando a ligação que está a ser desenhada está na posição correta, a ligação fica verde, assim como o contorno da conformação [13].

O Mechanisms é uma aplicação que, contrariamente às anteriormente referidas, é paga. Nesta aplicação estão envolvidos apenas dois tipos de reações de substituição e eliminação. As moléculas apresentam -se em modelos de linha (ligações químicas) e bola 
(átomos) e o jogador faz movimentar os átomos de modo a que ocorra a reação $[13,14]$.

O MILAGE Aprender+ ${ }^{1}$ é uma aplicação onde o professor pode colocar os conteúdos que pretende, disponibilizando exercícios e soluções, bem como a respetiva cotação. Os alunos realizam os exercícios propostos submetendo uma fotografia da solução. Após isto, o aluno pode visualizar a solução que havia sido disponibilizada pelo professor na aplicação e pode realizar a sua autoavaliação ou avaliar a resolução submetida por um colega. A aplicação permite assim a autoavaliação e a avaliação pelos pares o que ajuda o aluno a consolidar a matéria [16].

O Nomenclature Bets é um jogo online em que os estudantes do ensino secundário ao superior jogam em pares. A nomenclatura de compostos orgânicos é o tópico abordado numa competição divertida e envolvente onde os jogadores podem responder até 650 perguntas de escolha múltipla [17].

O Isomers é uma aplicação paga na qual são apresentados ao jogador vários átomos de carbono, e consoante a opção previamente selecionada pelo jogador: (1) faz ligaç̃ões entre os átomos de acordo com o(s) requisito(s) apresentado(s) pelo jogo; (2) a partir do nome indicado faz a estrutura do composto ou; (3) reproduz a estrutura do composto $[17,18]$.

\section{Conclusões}

0 recurso a jogos no ensino pode ser visto como uma estratégia para aumentar o interesse dos alunos por matérias menos atrativas ou com um maior grau de dificuldade. Neste sentido, o ensino e a aprendizagem da química orgânica pode ser potenciado pelo uso das aplicações de jogos existentes, sendo a sua maioria de uso livre.

\section{Notas}

${ }^{1}$ A aplicação foi desenvolvida inicialmente para trabalhar conteúdos matemáticos mas, atualmente, é utilizada em diversas disciplinas, nomeadamente no ensino de línguas, análise e modelação de sistemas e na química, mais especificamente na química orgânica.

\section{Referências}

[1] M. T. Crimmins, B. Midkiff, J. Chem. Educ. 94 (2017) 429-438.

[2] A. J. Franco-Mariscal, J. M. Oliva-Martínez, Á. Blanco-López, E. EspañaRamos, J. Chem. Educ. 93 (2016) 1173-1190.

[3] J. V. Russell, J. Chem. Educ. 76 (1999) 487.

[4] M. J. Welsh, J. Chem. Educ. 80 (2003) 426-427.

[5] E. Erdik, J. Chem. Educ. 80 (2003) 429-430.

[6 R. A. Kletsch, J. Chem. Educ. 55 (1978) 104.

[7] S. C. Farmer, M. K. Schuman, J. Chem. Educ. 93 (2016) 695-698.

[8] J. M. Carney, J. Chem. Educ. 92 (2015) 328-331.

[9] J. V. Russell, J. Chem. Educ. 76 (1999) 481.

[10] A. J. Williams, H. E. Pence, J. Chem. Educ. 88 (2011) 683-686.

[11] V. D. B. Bonifácio, J. Chem. Educ. 89 (2012) 552-554.

\section{$>$}

\section{${ }^{*}$ Custódia Fonseca}

É Professora Auxiliar do Departamento de Química e Farmácia da Universidade do Algarve. Os seus interesses cientíícos têm sido dentro da área de química orgânica e química farmacêutica, estudos mecanísticos de catálise heterogénea, isolamento de toxinas e estudo de compostos com atividade biológica. Enquanto docente, tem-se interessado pelo uso de novas tecnologias no seu ensino. cfonseca@ualg.pt ORCID.org/0000-0002-2480-3364.
[12] O. A. H. Jones, M. Spichkova, M. J. S. Spencer, J. Chem. Educ. 95 (2018) 1216-1220.

[13] J. Winter, M. Wentzel, S. Ahluwalia, J. Chem. Educ. 93 (2016) 1657-1659.

[14] "Mechanisms, app." [Online]. Disponível em: https://play.google.com/store/ apps/details?id=com.alchemiesolns. mechanisms\&hl=en_US.

[15] "Mechanisms, Webpage." [Online].Disponível em: https://www.alchem.ie/ mechanisms. [Acesso: 17/09/2019].

[16] "Milage Aprender+." [Online]. Disponível em: https://milage.ualg.pt/?page $\mathrm{id}=1176$.

[17] J. N. Da Silva Júnior et al., J. Chem. Educ. 95 (2018) 2055-2058.

[18] "Isomers, App." [Online]. Disponível em: https://play.google.com/store/ apps/details? id=com.alchemie.isomers\&hl=pt.

[19] "Isomers, webpage." [Online]. Disponível em: https://www.alchem.ie/isomers

\section{$>$}

\section{Marielba Zacarias}

É Professora Auxiliar no Departamento de Engenharia Informática e de Computadores da Universidade do Algarve, onde leciona disciplinas de Informática. Os seus interesses de investigação abrangem as áreas de arquiteturas e ontologias empresariais, desenho da interação homem-máquina, com foco especial no estudo da eficácia de tecnologias informáticas no ensino. mzacaria@ualg.pt ORCID.org/0000-0003-1640-2963. 